\title{
ACÇÃO SOCIAL DO ESTADO SOBRE A INSTRUCÇÃO PUBLICA
}

\section{Illustrada Congregação. Meus senhores.}

Além da acção juridica, diz Villaboim, pela qual o Estado garante a propriedade e o bem estar dos individuos em sociedade, impedindo que elles sejam perturbados na sua livre actividade, o Estado exerce uma outra' acção positiva e directa neste sentido. Depois de ter garantido aos individuos o desenvolvimento de sua intelligencia ou de suas forças, estabelecendo a ordem juridica e impedindo que um individuo perturbe outro na livre expansão de sua actividade, o Estado, dispondo das forças que muitas vezes lhe sobram do exercicio destas funcções primordiaes, exerce uma outra actividade positiva e directa em relação ao desenvolvimento das forças da nação. E'sta é a actividade social do Estado, objecto da Sciencia da Administração. Ora, sendo a sociedade... «l'insieme degli individui conviventi al fine del sodisfacimento degli umani bisogni», como diz Orlando (pag. 106, vol. 1.0), é facil comprehender como as várias neccessidades sociaes nas quaes o Estado intervem, devem coincidir com as dos individuos. Acha logar aqui a conhecida distincção entre necessidades physicas, economicas e intellectuaes «... e do mesmo modo que o individuo provê a sua saúde e o bem estar do seu corpo, assegura os seus meios de subsistencia, trabalhando, produzindo, trocando e consumindo os productos, e provê finalmente as suas necessidades intellectuaes procurando a cultura de que necessita, assim tambem a sociedade provê a analogas necessidades do corpo collectivo, repetindo-se a repartição e necessidades physico-sociaes, economicas e intellectuaes", como explica Orlando na pag. 106, vol. 1.॰.

E então a actividade social do Estado acha sua natural distincção systematica segundo a acção da administração pública e se exercita em alguma daquellas tres ordens de relações. A terceira fórma fundamental da actividade social, objecto da Sciencia da Administração, definida por Ferraris, pag 31, ed. 1880 de seus elementos e Sciencia dá Administração «...l'espositione metodica dei principii e delle teoriche relative all'azzione. 
sociale, positiva e diretta dello Stato", relativa á ingerencia nas relações intellectuaes, constitue a matéria da administração da cultura, subdividida segundo o gráo de instrucção em - instrucção primaria, superior e classica, technica e normal, conforme ensina Orlando. Este autor comprehende tambem nesta parte as instituições para o incremento das artes e subsidiarias para o desenvolvimento da cultura geral (conservatorios, galerias, bibliothecas, museus). E' ésta parte da sciencia que nos compete expôr.

1) "Puó l'azzione dello Stato estendersi alla vita morale della società ?", pergunta Cavagnari. Ferraris responde negativamente. Segundo este o Estado moderno não tem semelhante missão. Em conformidade com o principio de liberdade, a Moral é funccção privada e o Estado não se póde fazer regulador della. Si com sua acção na ordem economica physica e intellectual, o Estado dá aos individuos todas as condições externas de que depende a moralidade, e si tudo isto não basta para tornal-os honestos, que culpa póde ser imputada ao Estado? Comtudo admitte uma acção indirecta do Estado sobre a moralidade pública. Mas então cessa a competencia da Sciencia da Administração e surge a competencia da policia. Combate Cavagnari essa opinião do egregio Professor de Padua, e com elle está o nosso Viveiro de Castro, pag. 325. Ha com effeito um equivoco na opinião de Ferraris: não ha dúvida que o Estado «é impotente para tornar os cidadãos honestos»... mas não o será tambem a tornal-os ricos, sãos e intelligentes? Si o Estado deixasse de intervir nestas relações, ficaria sem objecto a Sciencia da Administração. Mas como das condições externas da moralidade, a instrucção é uma das mais importantes, ou quicá a mais importante, é claro que o Estado póde influir efficazmente sobre a vida moral do povo, promovendo a instrucção, que deve não só desenvolver a intelligencia, mas ainda formar o caracter. Não é scientificamente correcto separar a vida intellectual da moral, como não o é separar a instrucção da educação. A. educação deve ter a instrucção por base $\mathrm{e}$ garantia, e a instrucção deve ter como ideal o aperfeiçoamento do caracter e o desenvolvimento da moralidade, para que a intelligencia não se torne instrumento de 
maleficio para o individuo e para os outros membros da instrucção. Frederico Persico diz que a instrucção é o segredo da grandeza de um Estado, e pergunta "Quali sono i grandi secoli cio è i tempi in cui uno Stato fu più possenti e riverito? Quelli in cui più fiorirono le scienze, la leteratura, le leggi ciò è il pensiero di una nazione nelle sue varie forme (pag 308)". Tem razão Cavagnari: a instrucção bem entendida é um grande bem. A violenta crítica de Leroy «Beaulieu, Cap. $3{ }^{\circ}$ ». O Estado Moderno e suas Funcções, contra o fanatismo e o zelo infatigavel do Estado em promover a instrucção é só relativamente verdadeira. Diz elle que a instrucção não diminue os crimes, ainda que a instrucção póde exaltar o orgulho, e desejo da rápida fortuna, a mania dos empregos publicos, etc. Para elle, a instrucção deve ser considerada simplesmente «um instrumento que permitte ao homem utilizar melhor as suas forças e as que elle tem fóra de si e que além disso póde-lhe proporcionar certas satisfações, umas moraes, outras inoffensivas e outras condemnaveis». Ora, Cavagnari explica perfeitamente, como dissemos, que a instrucção deve ser moral, e sendo seu fim o aperfeiçoamento do caracter, não póde deixar de diminuir a criminalidade e aperfeiçoar o individuo. Vamos discutir agora outra questão: deve ser a instrucção obrigatoria? Diz Cavagnari: "O Estado não póde em regra constranger os cidadãos a instruir-se, primeiro porque «invito beneficium non datur» e depois porque nesta matéria de nada valeria a sancção da lei». Mas, si o constrangimento não é como diz Garelli della Morea, adaptavel ao que ha de mais livre, mais indeterminado no mundo, o espirito humano, si o dever da instrucção não póde converter-se em obrigação juridica, é ao menos moral. A unica excepção admissivel é a instrucção militar, porque o individuo, tendo obrigação de defender a Patria, tem tambem a obrigação de aprender a fazel-o. Ainda temos que estudar si o Estado não offende a liberdade obrigando os paes a dar instrucção elementar aos filhos. Viveiros de Castro, Ruy Barbosa, Virgili, collaborador de Orlando, e Stein, citado por Brunialti, proclamam a necessidade da instrucção elementar que serve para guiar o cidadão no caminho da vida. Stein diz mais: serve para tornar admissivel o cidadão no estado moderno. $\mathrm{O}$ homem ignorante é um perigo para 
a sociedade. O principio da obrigatoriedade foi primitivamente reconhecido na America do Norte pela lei de Conneticuti, de 1650, que obrigava o pae a enviar o filho á escola. Mais antigo ainda é o estatuto de Massachussets, 1648. Não se objecte que a obrigatoriedade vem ferir a soberania do pae de familia. Este não póde impedir o filho de se aperfeiçoar. Quando, por estolidez ou perversão moral, o queira fazer, o Estado deve intervir, tutelando o infeliz menor. A hi não ha attentado contra a liberdade, mas sim defesa dos entes desprotegidos. O grande argumento contra a instrucção obrigatoria é a liberdade. Palavra vã, méro sophisma.

Desse argumento entretanto usaram, segundo Virgili, Combes, Monod e Bourgeois, na celebre Enquête sur l'Enseignement secondaire, 1899, na França, escrevendo 6 grossos volumes... de pouca matéria. Argumentação fortissima desenvolveu Ruy Barbosa contra as idéas de Bourgeois. Com Cavagnari e Viveiros podemos dizer que as pessoas a educar não estão nas condições de sentir e conhecer as vantagens da instrucção. A necessidade de liquidos no organismo produz a sêde, mas justamente a falta de instrucção produz a falta do desejo della. $O$ ignorante não quer saber. $O$ pae ignorante impede que o filho saiba. Ao mesmo passo, $o$ individuo quanto mais sabe mais deseja saber. Goethe, morrendo no principio da primavera, saudoso do sol, exclamava: "Luz, luz, mais luz", assim o homem que sabe cada vez mais deseja aprender. E'sta obrigatoriedade só é possivel quanto á instrucção primaria que «pela sua simplicidade e limitação de seus fins, convem a todos os intellectoş, e a qualquer classe da sociedade», conforme ensina Cavagnari. A educação funccional, segundo Brunialti, exige vocação em que é bom juiz cada um da sua, e portanto não póde ser imposta. Consequencia da obrigatoriedade da instrucção primaria é sua gratuidade. Para segurança da exposição, vejamos as varias especies de instrucção. Segundo Stein, exposto por Brunialti, as attitudes do Estado marcam classes: I) O Estado assegura as condições primordiaes para o desenvolvimento individual, para o individuo poder ser membro da sociedade: instrucção primaria. Nota Cavagnari que ésta especie comporta não só saber lêr, escrever e contar, mas tambem prin- 
cipios fundamentaes de Moral. II) Tendo o Estado interesse em que os individuos procurem sua subsistencia, surge a educação funccionat. Não se refere só á instrucção mecanica, mas tambem a denominada liberal. III) Emfim a acção e a reacção entre as forças do iǹdividuo e do Estado e ahi surge a geral (pag. 669). Cavagnari dá como classes: I) a instrucção superior, II) a secundaria classica, III) a technica ou profissional e IV) a primaria. Quanto á primeira ha quatro systemas, que foram discutidos na Italia: I) ha universidades só literarias e outras só profissionaes; II) universidades dando laureas doutoraes e diplomas profissionaes; III) as laureas são dadas pelas universidades e os diplomas pelo Estado; IV) o systema que não distingue entre laurea e diploma. No Brasil o assumpto é regulado pelo dec. 11530. E' impossivel, mesmo resumidamente estudar a fundação e as vicissitudes por que passaram os institutos de instrucção superior de nossa Patria. Quanto á instrucção secundaria, a queixa na Italia é ser ella muito theorica. E'sta mesma queixa surge em outros povos. Helvetio condemna certos estudos como inuteis. Mas, conforme ensina Spencer, ha grande difficuldade em saber-se o que é util e o que é inutil em matéria de instrucção. Diz Spencer que se poderia tirar até algum proveito com as intrigas das comadres. No mesmo sentido Veron conta um caso succedido na França. Napoleão I, desejando dar um cunho práctico á instrucção, aboliu o estudo do latim. $O$ resultado foi que os alumnos que não frequentavam mais as aulas de latim tinham difficuldade maior para resolver os problemas de geometria. Verificou-se assim ser a lingua latina uma boa gymnastica intellectual, e portanto um estudo util. Viveiros de Castro cita como technicos, no Brasil: o instituto de surdos-mudos, de cégos, as escolas normaes e as escolas profissionaes femininas. A instrucção primaria, conforme ensina Viveiros, está a cargo dos municipios, auxiliados pelo Estado. Compete á União, pelo art. 35 $\S \S 2,3$ e 4 "animar o desenvolvimento das letras, artes e sciencias, crear instituições de ensino superior e secundarios nos Estados, e provêr á instrucção secundaria no Districto Federal». Interessante é o que refere Brunialti sobre a origem do ensino universitario. Algumas particularidades notaveis sobre o assumpto e valiosas para o Direito encontram-se em Cesar Cantu e 
na Historia do Direito Romano da Edade Média de Savigny. A principio só se ensinava o manejo das armas e o necessario para as funcções espirituaes. Foi Carlos Magno que creou a instrucção classica como base da instrucção funccional, locução de Stein e Brunialti. Ficou á Egreja pertencendo nos mosteiros e sédes dos bispados a educação ecclesiastica, e ás universidades a scentifica, livre ou leiga. A universidade preparava as peissoas para o serviço do Estado que começava. a surgir. Era um ensino especial. Ensinava-se Direito para os homens destinados ás funcções do Estado, Philosophia para os que se destinavam ao magisterio e emfim Medicina. Accentuou-se ésta differença nos seculos 17, 18 e 19 de modo a distinguir-se perfeitamente a instrucção preparatoria da especial ou funccional. Classico se tornou então o nome gymnasio para os estabelecimentos onde 'se estudam preparatorios, e o nome faculdade para os de estudos de matérias especiaes. Diz Brunialti que as faculdades dão as aptidões ou faculdades para o exercicio de varios ramos de serviços ainda que só publicos (pag. 686). Brunialti colloca ao lado da instrucçâo funccional, a economica, comprehendendo as escolas agrarias, florestaes, de minas e industriaes (pag. 692). Vamos passar a outro assumpto: deve a instrucção ser dada pelo Estado ou tamıbm pelo particular? Deve o ensino ser livre ou só official? Questão ésta é que não se confunde com a da liberdade profissional. Muitos argumentos foram apresentados por Smith em pról da instrucção particular: I) Vivendo o professor particular do honorario dado pelo público, tem interesse de dar melhor instrucção, aliás perderia o cliente. II) Achando-se, em regra, o professor público sob direcção de collegas, tem nestes cumplices. III) $\mathrm{O}$ professor público, com a vida segura, não tem interesse em ter bom nome.

Leroy Beaulieu ainda apresenta como defeito do ensino official tornar-se atrazado, immovel. Cavagnari responde a todos estes argumentos dizendo que a instrucção official é um facto consumado, e que o Estado nunca admittirá a sua extincção, soffrendo uma capitis deminutio. Parece fraco o argumento: lucta-se hoje pela liberdade do ensino, e a idéa tem caminhado. Cumpre pois estudar o assumpto. Minha opinião é que a liber- 
dade de ensino não tem dado bom resultado, e contra factos não ha argumentos. Segundo Reintiens na Inglaterra a liberdade de ensino tem dado péssimo resultado, e o mesmo se tem observado na America do Norte.

A experiencia é pois argumento decisivo. Contra a instrucção dada por particulares estão Mattew Arnold, Lerman (de Kansas), Jillson (de Carolina) e Horacio Mann. Entendo que, si no futuro se achar meio de combater todos os defeitos da instrucção particular, convirá acceital-a pelas suas vantagens. Por agora, sendo avultados os seus defeitos, cumpre toleral-a com muitas cautelas, quasi a titulo de experiencia. Para dar ao professor público, o incentivo do particular, recommenda Cavagnari que paguem os alumnos parte do honorario. Por vezes temos feito alguma coisa de semelhante no Brasil.

E'sta medida de cautela, diz Cavagnari, será impossivel em relação ás escolas primarias porque devem ser gratuitas. Si o Estado admittisse qualquer remuneração para o professor primario, teria como mostrou Fornelli, citado por Virgili, o ensino público nos nossos tempos (cap. 14 a 16) teria por concurrentes só os individuos movidos por sentimentos religiosos. Sería a morte do ensino official e o estabelecimento do clerical. Tolerada no Brasil a instrucção secundaria e a superior ministrada por particulares, grande vigilancia do Estado deve ser estabelecida.

Longas paginas ha sobre o assumpto de Viveiros de Castro inspirado em Ruy Barbosa e Cavagnari. $O$ ensino particular abandonado leva ao triumpho dos mais habeis em illudir os incautos ou imprecatados, que são geralmente os paes pouco preparados para julgarem a competencia dos mestres. E já nos dizia Stuart Milk que, no caso, o consumidor não é o melhor juiz da mercadoria.'

O Estado intervem, diz Cavagnari, de modo indirecto: I fiscalizando a idoneidade dos docentes. II fiscalizando a disciplina da escola. IIL fiscalizando os exames por meio de funccionarios públicos (pag. 273). Temos no Brasil por diversas leis adoptado ésta última medida. Ainda como medidas indirectas para animação e protecção ao ensino particular, póde o Estado usar 
de subsidios, premios e toda sorte de recompensas. $\mathrm{Si}$, como diz Bluntschlí, o Estado não póde fazer um bom verso póde entretanto encorajar a poesia.

Lembra Cavagnari, de accordo com Leroy Beaulieu que é preciso ter prudencia na concessão de auxilios para não proteger aos mediocres e aos maus. Só na America do Norte deu bom resultado a idéa defendida por Leroy de viverem os collegios e estabelecimentos de instrucção de donativos particulares. No Brasil o mais accentuado tempo de desofficialização do ensino foi o do regimen do decreto 8659 .

Vamos tractar da questão que se inscreve: deve ser o ensino religioso ou leigo? 'E' questão sobre que ha uma avalanche de publicações, segundo diz Virgili. Accrescenta elle que ésta questão apparece de tempos a tempos. Vexata quæstio, disputa de campanario. Não significa a solução pela instrucção leiga espirito pouco religioso. Ruy Barbosa adopta a opinião radical a favor do ensino leigo, não obstante ser catholico. Não ha moral sem religião, mas ésta póde ser um postulado nas licções de Moral nas escolas leigas.

Exemplo frisante temos na lei de Massachussets: «O professor deve esforçar-se por inspirar ao alumno, piedade, justiça, respeito á verdade, amor á patria, caridade para com o proximo, sobriedade, amor ao trabalho, castidade, moderação, temperança e outras virtudes! A Moral Christã, acceita por todos os povos cultos e mesmo pelos livres pensadores, numero aliás pequeno na sociedade moderna, deve ser cultivada com amor.

Dois argumentos apresenta Virgili contra a escola com ensino religioso: I (fraco) a religião é sentimento individual, o Estado não é religioso e não póde ensinar religião que não tem, e nem póde ter, II (forte) vão á escola creanças de crenças diversas, e portanto é inconveniente a imposição do mesmo ensino religioso a todos os alumnos. Ruy Barbosa diz que as relações entre o Fstado é a Egreja suggeriram quatro systemas: I ensino religioso obrigatorio a todos os alumnos, II ensino religioso pelo professor civil, mas facultativo, III ensino religioso no predio da escola, por professor extranho, ministro da religião do alumno, IV ensino religioso banido do edificio e do programma. O primeiro offende á liberdade de consciencia. Não quero o 
Estado atheu, mas tolerante. O segundo tem dois inconvenientes: ou o professor leigo não tem fé, e periga o ensino religioso, ou o professor é crente e fica prevenido contra o alumno de credo differente. $O$ terceiro não offerece nenhuma vantagem. $O$ ensino poderia ser dado de preferencia no templo respectivo.

Por exclusão, conclue-se que o ensino religioso deve ser expellido da escola, aconselhando apenas o Estado e o professor a religiosidade, grande força para a moralização do individuo. Argumento decisivo contra o ensino religioso na escola é tirado dos factos: no Brasil não diminuiu a fé com o desapparecimento do ensino religioso das escolas.

No Direito positivo, temos o art. $72 \S 6 .^{\circ}$ da Constituição Federal que baniu o ensino religioso das escolas. Passemos a estudar a instrucção technica. Segundo Brunialti, ha na Inglaterra as escolas denominadas reaes. Em França o movimento a favor da instrucção technica foi iniciada por João Jacques Rousseau, o defensor da educação technica. Pouco ha de constituido sobre o assumpto, comquanto seja objecto de estudos notaveis de homens da estatura de Huxley, "Discursos sobre a Educação". As obras juridicas são omissas a respeito. Ha monographias importantes sobre a instrucção technica. E'sta foi, por muito tempo, secreta.

$\mathrm{E}^{\prime}$ tradicional o rigor do segredo das corporações de officios na Italia. Guardava-se cuidadosamente o segredo da fabricação da porcellaná, dos tapetes de Gobellins etc., e quem contava o segredo era punido com a pena de morte. Excusado é dizer a importancia da instrucção technica para o nosso paiz. Pouco se tem feito entre nós, comtudo temos alguns institutos como o D. Anna Rosa, as secções diversas das escolas normaes, os lyceus de artes e officios, a secção profissional do Instituto dos Cégos, etc. O tempo não nos permitte exame mais aprofundado da matéria. Vejamos a influencia indirecta do Estado na cultura do povo por meio da ingerencia no dominio das artes: a architectura, a pintura, a musica, a poesia e a literatura em geral. Diz Bluntschli que a arte tem maior influencia no povo do que a sciencia. Goethe e Schiller tiveram mais influencia na Allemanha do que os maiores scientistas. $\mathrm{E}$ a arte pelo seu tradicionalismo mitiga os defeitos da nossa civilização actual desprezadora das tradições. (Bateu a hora).

Braz de Souza Arruda. 